\title{
BILINGUISMO, TRADUÇÃO E INTERPRETAÇÃO: PERCEPÇÃO DOS CLIENTES QUANTO AOS PROFISSIONAIS CONTRATADOS
}

\author{
Ana Carolina Moura Pompeu ${ }^{1}$ \\ 1Pontifícia Universidade Católica do Rio Grande do Sul, Porto Alegre, Rio \\ Grande do Sul, Brasil
}

Patrizia Cavallo²

${ }^{2}$ Universidade Federal do Rio Grande do Sul, Porto Alegre, Rio Grande do Sul,

Brasil

\begin{abstract}
Resumo: O presente artigo tem como objetivo investigar a percepção dos clientes quanto ao profissional que contratam para traduzir e/ou interpretar. Para tais clientes, ser bilíngue é o suficiente para caracterizar alguém como um bom tradutor e/ou intérprete? A primeira seção deste trabalho, de cunho teórico, visa a revisar alguns estudos sobre conceitos de bilinguismo e outros que comparam as habilidades de tradutores e intérpretes profissionais com aquelas de bilíngues sem formação e/ou experiência nestas áreas, além de tratar brevemente acerca das diferenças entre tradução e interpretação. A segunda parte descreve a metodologia deste estudo, o qual envolveu a preparação de um questionário e o seu envio para algumas empresas e instituições do Estado do Rio Grande do Sul (Brasil), bem como traz uma análise dos dados obtidos.
\end{abstract}

Palavras-chave: Percepção; Tradução; Interpretação; Bilinguismo

\section{BILINGUALISM, TRANSLATION AND INTERPRETING: THE PERCEPTION OF CLIENTS REGARDING THE PROFESSIONALS THEY HIRE}

Abstract: The purpose of this article is to investigate the perception of clients regarding the translation and/or interpreting professionals they 
hire. For such clients, is being bilingual enough to be a good translator and/or interpreter? The first part of this paper provides a theoretical overview of some studies on the concepts of bilingualism and others that compare the skills of professional translators and interpreters with those of untrained and/or inexperienced bilinguals, while also briefly discussing the differences between translation and interpreting. The second part describes the methodology, which involved preparing a questionnaire and sending it to companies and institutions in the State of Rio Grande do Sul (Brazil), and analyzing the data obtained.

Keywords: Perception; Translation; Interpreting; Bilingualism

\section{Introdução}

Muitas vezes, as atividades de tradução e interpretação são confundidas com a habilidade de pessoas que têm o conhecimento de duas línguas, os assim chamados bilíngues. Falar mais de uma língua é diferente de ser um tradutor ou intérprete com formação e/ ou experiência nestas áreas, treinado para realizar tais atividades. Muitas empresas brasileiras, principalmente as que exportam para outros países, como as multinacionais ou empresas que precisam divulgar seu produto para a comunidade internacional, precisam dos serviços de tradução e/ou interpretação.

Tendo em vista a arraigada - e errônea - concepção que pessoas leigas na área da Tradução, Letras e afins possuem a respeito das habilidades de bilíngues sem formação e/ou experiência e de tradutores e intérpretes profissionais, acreditamos ser relevante levantar dados concretos sobre essa percepção. É necessário investigar os mecanismos do mercado da tradução e da interpretação, até para auxiliar na formação nestas áreas e para propiciar uma eventual sensibilização sobre a importância da categoria como um todo.

Assim, essa pesquisa ${ }^{1}$ tem por escopo investigar a percepção dos

${ }^{1}$ Uma versão ampliada deste trabalho foi apresentada, em 2018, por Ana Carolina Moura Pompeu, sob orientação acadêmica de Patrizia Cavallo, como trabalho de conclusão no âmbito da Especialização em Estudos em Tradução: Teorias, 
clientes quanto ao profissional contratado para traduzir e/ou interpretar, especialmente no que diz respeito a sua consciência das diferenças entre bilinguismo e atividades especializadas de tradução e interpretação. Para tanto, elaboramos um questionário e selecionamos algumas empresas e instituições do Rio Grande do Sul para respondê-lo. O objetivo da pesquisa foi investigar qual o tipo de profissional buscado pelas pessoas que contratam serviços de tradução e/ou interpretação. Temos como hipótese a percepção de que a formação e/ou experiência profissional em tradução/interpretação não é tão importante para a maioria dos clientes e que, na visão deles, o fato de ser bilíngue já seria suficiente para traduzir ou interpretar.

Com frequência, os estudos que envolvem bilinguismo e tradução e/ou interpretação testam as habilidades de bilíngues sem formação e profissionais especializados na área de tradução e/ou interpretação (Dillinger; Ibañez, Macizo e Bajo; Yudes, Macizo e Bajo). No entanto, pouco se sabe sobre a percepção dos clientes que contratam esses serviços. Na literatura, percebemos a inexistência de um consenso entre os estudiosos acerca da definição de bilinguismo. Assim, apresentamos algumas definições recentes sobre esse conceito, bem como alguns estudos que tiveram grande impacto na área e que falam sobre a habilidade do bilíngue comparada à tradução. Além de falar sobre bilinguismo, torna-se imprescindível esclarecer a distinção entre as atividades de tradução e interpretação, pois há diferença significativa quando comparamos as duas atividades.

\section{Fundamentação teórica}

Ser bilíngue é o suficiente para transformar alguém em um bom tradutor ou intérprete? Para responder, inicialmente é preciso definir o termo bilinguismo. Esta definição é importante, uma vez que muitas pessoas fora da área da Tradução, Letras ou afins parecem acreditar que, para um bom tradutor ou intérprete, basta ser bilín-

Práticas e Tecnologias da PUC-RS, com o título “A percepção dos clientes quanto aos serviços de tradução e/ou interpretação: ser bilíngue é suficiente?”.

Cad. Trad., Florianópolis, v. 39, no 3, p. 90-110, set-dez, 2019. 
gue. Podemos afirmar isso a partir de vários relatos de colegas que têm conhecimento de duas (ou mais) línguas, mas não são formados e nem possuem experiência em tradução e/ou interpretação e, apesar disto, recebem pedidos para traduzir trabalhos acadêmicos, websites e até mesmo interpretar palestras.

Para muitos estudiosos, ser bilíngue significa dominar duas línguas fluentemente. Outros acreditam que o bilíngue não tem sotaque em nenhuma das línguas, que ele se "passa" por um nativo, ao passo que existem ainda aqueles que afirmam que, para ser bilíngue, é preciso ter aprendido as duas línguas desde criança. Nesse artigo, ao mencionarmos o "bilíngue", referimo-nos a alguém com conhecimento em duas línguas, mas sem formação e/ou experiência em tradução ou interpretação.

Năznean esclarece que alguns pesquisadores definem o bilinguismo como o processo de alternar o uso de duas línguas, mas não concorda com essa definição, pois, segundo ela, o conceito de bilinguismo pode se referir a diferentes situações, tais como a criança que fala uma língua com a mãe e outra com o pai, ou o aluno alemão que estuda inglês, entre outros.

Segundo Grosjean, a maioria dos bilíngues não possuem a mesma fluência nas duas línguas, muitos têm sotaque em pelo menos uma delas e outros adquirem a outra língua na adolescência ou na fase adulta. Ainda segundo o autor, os bilíngues usam as línguas para finalidades diferentes, em diversas fases da vida e com objetivos diferentes, assim como o nível de fluência na língua depende da necessidade de cada indivíduo. Grosjean conclui que muitos bilíngues são mais fluentes em uma língua do que na outra e que alguns não conseguem ler ou escrever em uma das suas línguas.

Johnson traz uma definição de bilinguismo relevante, afirmando que, para um aluno iniciante de interpretação, o bilíngue é capaz de compreender e ser compreendido em uma conversa "adulta" na segunda língua com um adulto monolíngue nessa segunda língua.

Ainda assim, para ele, mesmo os alunos mais proficientes perceberam que ser bilíngue não era suficiente, pois interpretar e traduzir não são atividades genéricas. Johnson explica que um 
bilíngue é capaz de expressar suas próprias ideias nas duas línguas e, às vezes, a pessoa prefere uma língua à outra, dependendo do contexto. Traduzir e interpretar são atividades em que o tradutor e o intérprete necessitam captar a ideia do outro. A habilidade de transferir essa ideia para outra língua sem perder o sentido original é o elemento crucial que distingue as habilidades de um tradutor e de um intérprete das habilidades de um bilíngue.

$\mathrm{Na}$ literatura sobre tradução, interpretação e bilinguismo, deparamo-nos também com o conceito de tradução natural (natural translation) trazido por Harris. Segundo ele, tradução natural é aquela feita por bilíngues em circunstâncias cotidianas sem treinamento especial. Harris afirma que todo tradutor tem que ser bilíngue e que todo bilíngue consegue traduzir. No entanto, Grosjean não concorda com essa afirmação, pois, segundo ele, normalmente os bilíngues não são bons tradutores e intérpretes. Grosjean explica que traduzir e interpretar não requer apenas habilidades específicas, mas exige que o profissional tenha conhecimento lexical idêntico nas duas línguas, algo que o bilíngue não possui.

Segundo Lörscher (5), várias razões contribuem para que a afirmação de Harris ("todo bilíngue consegue traduzir") não seja corroborada: a) apesar de os bilíngues possuírem competência em duas línguas, essas competências normalmente não são as mesmas, e pode ser que ele seja competente em um tópico específico da língua $\mathrm{A}$, mas não da língua $\mathrm{B}$; b) os bilíngues normalmente são carentes da consciência metalinguística e metacultural necessárias para traduzir um texto fonte para a língua e cultura alvo; e c) a competência bilíngue em duas línguas não necessariamente inclui a competência em traduzir significados de uma língua para a outra.

A seguir, relataremos algumas pesquisas que comparam o desempenho de tradutores e intérpretes profissionais ao lado de bilíngues sem experiência em tradução ou interpretação em algumas atividades de leitura e produção oral. Dillinger comparou intérpretes profissionais e bilíngues quanto ao processo de compreensão durante uma interpretação. O pesquisador encontrou uma pequena diferença quantitativa (compreensão mais eficiente) e nenhuma diferença qualitativa 
(compreensão com diferença de significado). Segundo o autor, os resultados sugerem que habilidades especiais de compreensão dos intérpretes experientes podem aparecer em situações com materiais mais difíceis e com ritmo de apresentação mais rápido.

Outro estudo que comparou intérpretes profissionais, bilíngues e monolíngues foi o de Yudes, Macizo e Bajo, em que os intérpretes profissionais apresentaram vantagem nas atividades diretamente relacionadas às tarefas de interpretação, mostraram maior flexibilidade mental do que os bilíngues e foram mais rápidos na troca de hipóteses quando necessário. Segundo os autores, isso se deve, provavelmente, à habilidade que o intérprete profissional tem de alternar entre duas línguas e de monitorar e corrigir seu próprio output enquanto reformula e produz na língua alvo. Porém, corroborando a hipótese dos autores, e em consonância com o estudo de Ibañez, Macizo e Bajo no qual se afirma que os intérpretes não inibem a língua alternativa enquanto interpretam, os intérpretes profissionais não tiveram melhor performance do que os bilíngues e os monolíngues ao ignorar informações conflitantes (tarefa de Simon).

O estudo de Ibañez, Macizo e Bajo envolveu tradutores e bilíngues sem experiência em tradução, e teve como instrumento a leitura de frases randômicas nas duas línguas dos participantes. $\mathrm{O}$ estudo mostrou que os tradutores profissionais foram mais rápidos no processamento de palavras cognatas em relação às palavras-controle, indicando que as duas línguas dos participantes estavam ativas durante a leitura. Além disso, os tradutores não pareceram inibir a língua irrelevante, uma vez que não havia custo de troca assimétrico (a troca para a língua mais dominante). Em contrapartida, os bilíngues apresentaram alto custo de troca quando da troca para a L1, diferentemente do que acontecia durante a troca para a L2 (aqui houve troca assimétrica), indicando que eles inibiram a língua que não era alvo quando compreendiam frases na outra língua. Ademais, os bilíngues processaram as palavras cognatas e as palavras-controle na mesma velocidade, indicando que somente a língua em que as frases eram apresentadas foi selecionada. Segundo os autores, esses resultados indicam que o treinamento formal em tradução também é 
um fator modulador, assim como o contexto linguístico e semântico, a proficiência linguística, a carga exigida da memória de trabalho e a similaridade ortográfica quando se trata da seleção da língua.

Além de falar sobre bilinguismo, é importante esclarecer a diferença entre as atividades de tradução e interpretação. São tarefas que estão relacionadas, mas diferem significativamente em termos de treinamento, aptidão e até mesmo proficiência na segunda (ou terceira) língua. A principal diferença é o modo de comunicação: enquanto a atividade de tradução é efetuada na forma escrita, a interpretação é realizada oralmente.

Segundo Christoffels, em uma perspectiva cognitiva, a diferença entre tradução e interpretação é significativa, pois distintos processos cognitivos estão envolvidos durante a realização dessas tarefas. A interpretação, especialmente a simultânea, é vista como uma das atividades linguísticas mais complexas porque novas informações são apresentadas enquanto o intérprete simultaneamente compreende o input em uma língua e produz o output na outra. $\mathrm{Na}$ atividade de tradução, o processamento de informação é diferente em termos de carga cognitiva. Na tradução, o indivíduo acessa recursos internos e externos ao mesmo tempo, pois tem a oportunidade de usar dicionários, consultar colegas e até mesmo o autor do texto-fonte, além do seu próprio conhecimento. Já o intérprete precisa se preparar com antecedência e utilizar os recursos extralinguísticos fornecidos no momento da interpretação para ajudar na sua compreensão, uma vez que pode visualizar quem ele está interpretando, bem como os slides apresentados na palestra.

Schwieter e Ferreira afirmam que interpretar envolve superar problemas que devem ser resolvidos enquanto a atividade é executada sem atraso na produção da língua-alvo. Na tradução, os problemas podem ser revisitados posteriormente ao mesmo tempo em que o texto-alvo continua sendo traduzido. Um problema de tradução pode ser corrigido e revisado sem que o leitor do texto-alvo perceba as dificuldades encontradas durante a tradução. Contudo, na interpretação, correções e erros são notados pelos ouvintes e, dependendo da sua gravidade, resultam na perda da credibilidade do intérprete. 
Apesar de a maioria das pesquisas apresentar resultados parecidos ao comparar o desempenho entre tradutores/intérpretes profissionais e bilíngues, resultados mais evidentes são observados nos profissionais quando as habilidades testadas envolvem atividades características da tarefa de traduzir ou interpretar, como, por exemplo, a eficiência nas habilidades que envolvem a memória de trabalho, a coordenação dos processos verbais e a alta performance em acessar as representações semântico-lexicais (Bajo, Padilla e Padilla).

A seguir, será apresentada a pesquisa aqui desenvolvida, sua metodologia e a análise dos dados obtidos através da aplicação do instrumento de coleta elaborado.

\section{Descrição da pesquisa e análise dos dados}

O estudo consistiu em uma pesquisa de campo transversal aplicada em algumas empresas e instituições do Estado do Rio Grande do Sul. Para a sua realização, foram selecionadas empresas e instituições (entre essas, associações científicas e profissionais) de impacto local e com renome na região, levando em consideração a provável utilização dos serviços de tradução e/ou interpretação. Instituições como universidades e editoras não foram incluídas por desenvolverem atividades muito próximas da área de Letras e Tradução, pois nosso objetivo era avaliar a percepção de clientes "comuns" e não daqueles familiarizados com a área. Com base nesses critérios, quarenta e cinco empresas e instituições foram incluídas como participantes. Os dados gerais (nome, telefone, e-mail e website) foram obtidos através de pesquisa online e armazenados em uma tabela do programa Excel.

Paralelamente, foi elaborado um questionário (Pompeu) constituído de seis perguntas fechadas e duas semiabertas.

Hill e Hill (162) listam algumas instruções comuns a serem colocadas em um breve texto no início do questionário: a) um pedido de cooperação para o seu preenchimento, b) a razão da aplicação do questionário, c) o nome da instituição à qual a pesquisa está 
vinculada, d) uma declaração formal de confidencialidade das respostas e, ao final, e) uma declaração formal da natureza anônima do questionário. Todos os itens acima foram incluídos no nosso instrumento, bem como um Termo de Consentimento Livre e Esclarecido, que inclui, na ordem, os itens "c", "b", "d" e "e". O item "a" consta no corpo do e-mail enviado a cada participante.

Após a confecção das perguntas e a elaboração do termo, o questionário foi inserido na ferramenta Google Docs, tornando possível enviá-lo através de um link, criado pelo próprio site, que foi copiado e colado no corpo do e-mail encaminhado ao participante. Antes de enviar os e-mails, as empresas e instituições selecionadas foram contatadas por telefone. Assim, o questionário acabou sendo enviado para quarenta das quarenta e cinco empresas e instituições listadas, pois algumas alegaram não utilizar o serviço ou não participar de pesquisas acadêmicas.

O questionário ficou disponível online por um mês, período considerado hábil tanto para o bom retorno dos participantes quanto para os prazos deste estudo.

\subsection{Análise dos dados}

Nesta seção serão apresentadas as respostas obtidas, bem como a análise delas à luz da literatura abordada na parte de fundamentação teórica e com base em Alexander et al., único estudo encontrado que aborda questões parecidas com as que motivaram a nossa pesquisa, embora foque no serviço de interpretação e os "clientes" sejam os imigrantes. O retorno obtido através do envio do questionário foi superior às expectativas, eis que, dos quarenta enviados, vinte e um foram respondidos.

No caso da primeira pergunta, "A sua empresa/instituição utiliza, ou já utilizou, serviços de tradução e/ou interpretação?”, mesmo que a resposta fosse negativa, seria possível continuar o questionário, pois tanto no e-mail enviado quanto no contato telefônico foi informado que, caso o serviço nunca tivesse sido utilizado, o respondente poderia pensar em quais critérios utilizaria para a con- 
tratação do serviço no futuro. Conforme mostra o gráfico $1^{2}$, foram obtidas 21 respostas para a primeira pergunta. Contudo, durante a descrição dos resultados, notamos que nem todas as perguntas do questionário foram respondidas pelos 21 participantes.

Gráfico 1 - “A sua empresa/instituição utiliza, ou já utilizou, serviços de tradução e/ou interpretação?"

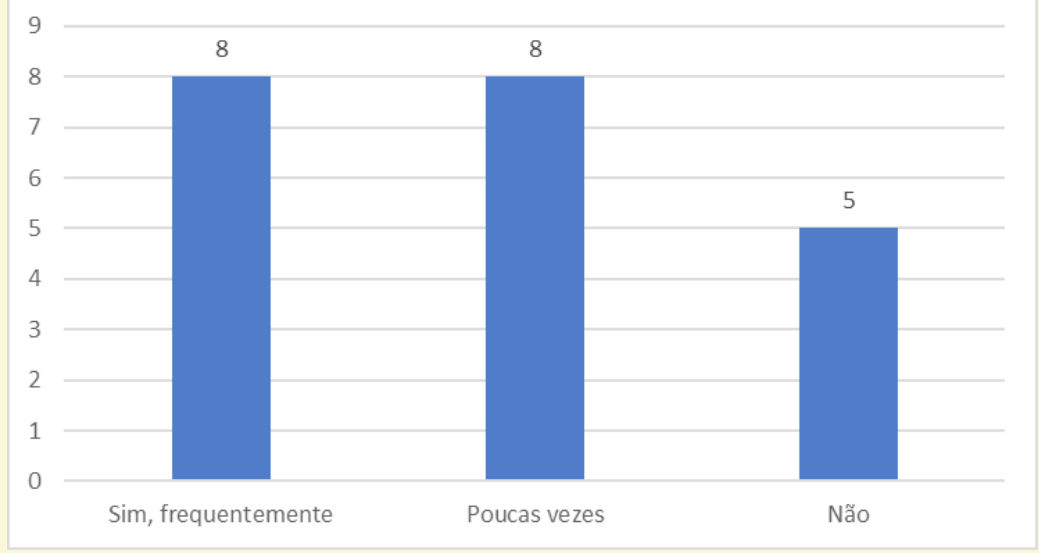

Fonte: Elaborado pelas autoras.

O gráfico 1 mostra que apenas $23,8 \%$ das empresas e instituições respondentes não utiliza, ou ainda não utilizou, o serviço de tradução e/ou interpretação, e que 76,2\% já o utilizaram alguma vez, atestando que a grande maioria dos participantes selecionados já teve experiência com a contratação de tais serviços, fato que realça a importância da área nos tempos atuais.

Com a pergunta 2, "Como ocorre, ou ocorreu, a contratação desse serviço?", foi possível observar de que forma o profissional é contratado para executar o serviço e, consequentemente, quem seria o profissional em questão. Tanto nas perguntas quanto nas opções de resposta optou-se por não utilizar o termo "bilíngue",

2 Em todos os gráficos, o eixo vertical corresponde ao número de respostas e o eixo horizontal às opções de respostas.

Cad. Trad., Florianópolis, v. 39, no 3, p. 90-110, set-dez, 2019. 
mas sim "funcionário que realiza esta função", pois o público leigo poderia se confundir com um conceito tão vasto.

Para essa pergunta, foram obtidas 18 respostas; dentre elas, $77,7 \%$ dos respondentes pareceram se preocupar com o tipo de serviço contratado, pois disseram contratar esse serviço por meio de agência de tradução ou diretamente com o profissional especializado, preferindo, então, tal opção àquela de um funcionário com conhecimento bilíngue $(22,2 \%)$. Nenhum dos respondentes afirmou ter um tradutor e/ou intérprete contratado na sua empresa/ instituição, confirmando uma tendência da profissão de tradutores e intérpretes, que é trabalhar mais na qualidade de autônomos do que como funcionários de uma empresa.

Gráfico 2 - "Como ocorre, ou ocorreu, a contratação desse serviço?"

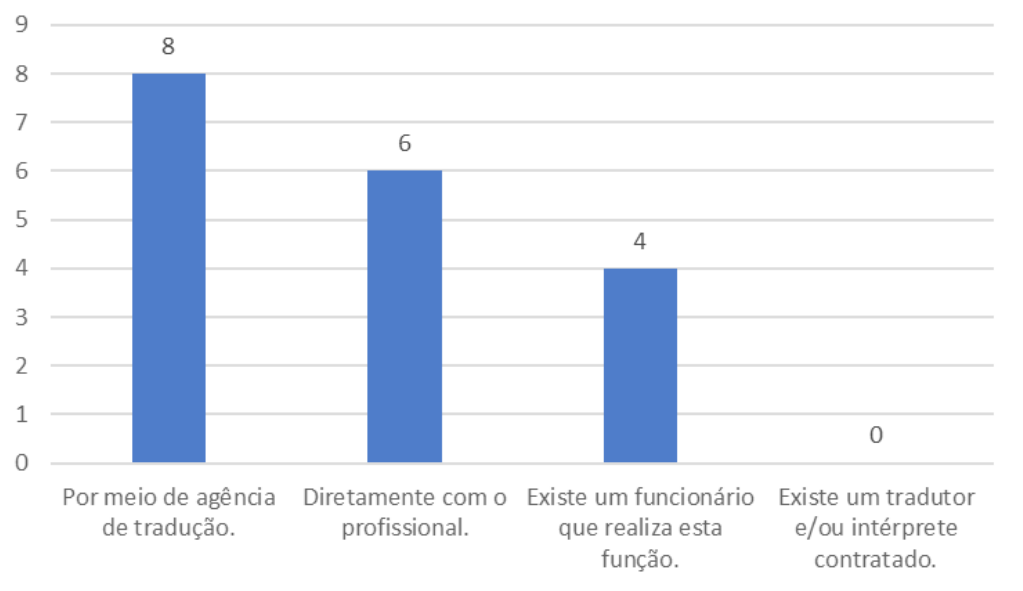

Fonte: Elaborado pelas autoras.

Na terceira pergunta, "Caso a contratação seja por agência, como se dá a escolha da agência contratada (ou como você escolheria, mesmo que a sua empresa/instituição não tenha essa experiência)?", 67\% dos respondentes afirmaram contratar agências recomendadas por clientes ou funcionários, $22 \%$ se preocuparam com o renome da agência no mercado e apenas $11 \%$ mencionaram 
o menor orçamento, demonstrando a predileção pela qualidade ao invés do preço menor.

Gráfico 3 - "Caso a contratação seja por agência, como se dá a escolha da agência contratada (ou como você escolheria, mesmo que a sua empresa/instituição não tenha essa experiência)?”

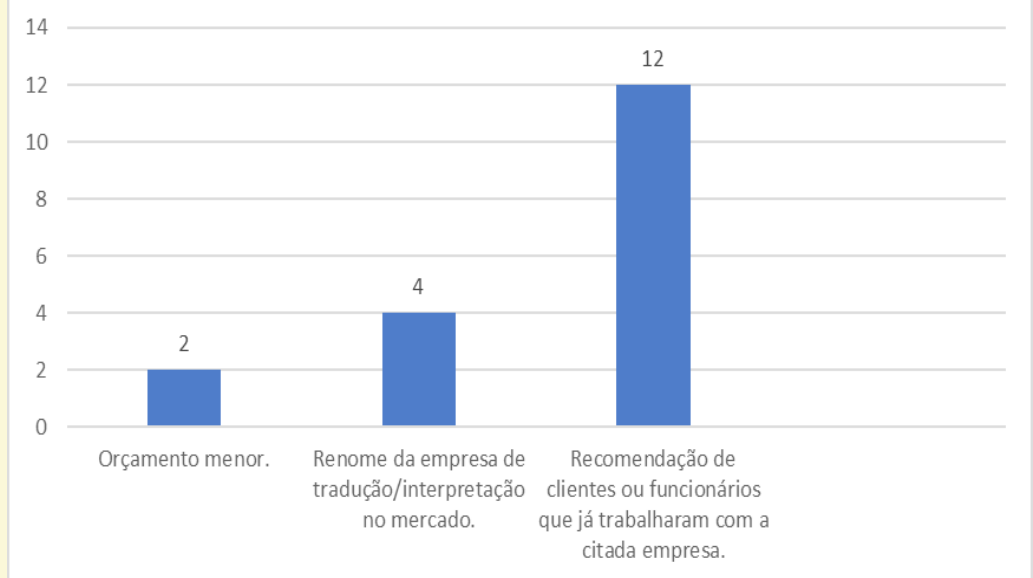

Fonte: Elaborado pelas autoras.

A próxima pergunta, "No caso de contratação direta com o profissional, quais são os requisitos básicos exigidos para a contratação do tradutor/intérprete?", obteve um total de 19 respostas. A maior parte, $63,1 \%$, disse que ser profissional especializado na área de tradução e/ou interpretação, com curso de graduação e/ou pós-graduação, é requisito básico para a contratação de um tradutor e/ou intérprete. Apesar do resultado, alguns respondentes (26,3\%) acreditam que ser especialista na área da empresa ou instituição, sem formação e/ou experiência em tradução/interpretação, mas com conhecimento das línguas estrangeiras requeridas, é suficiente. A opção "ter morado no exterior" não obteve nenhuma escolha, ao passo que $10,5 \%$ acredita que basta ser nativo da língua solicitada.

O resultado demonstra que, apesar de a maioria dos clientes preferir contratar um tradutor e/ou intérprete profissional, ainda exis- 
tem aqueles que optam por contratar um profissional especialista na área de atuação da empresa e/ou instituição e que conheça as línguas solicitadas. Esses dados nos fazem refletir sobre a possibilidade desse especialista ser um funcionário da empresa, conforme mostram os dados do gráfico 2, em que 4 respondentes disseram ter um funcionário que realiza a função de traduzir e/ou interpretar.

Gráfico 4 - "No caso de contratação direta com o profissional, quais são os requisitos básicos exigidos para a contratação do tradutor/intérprete?"

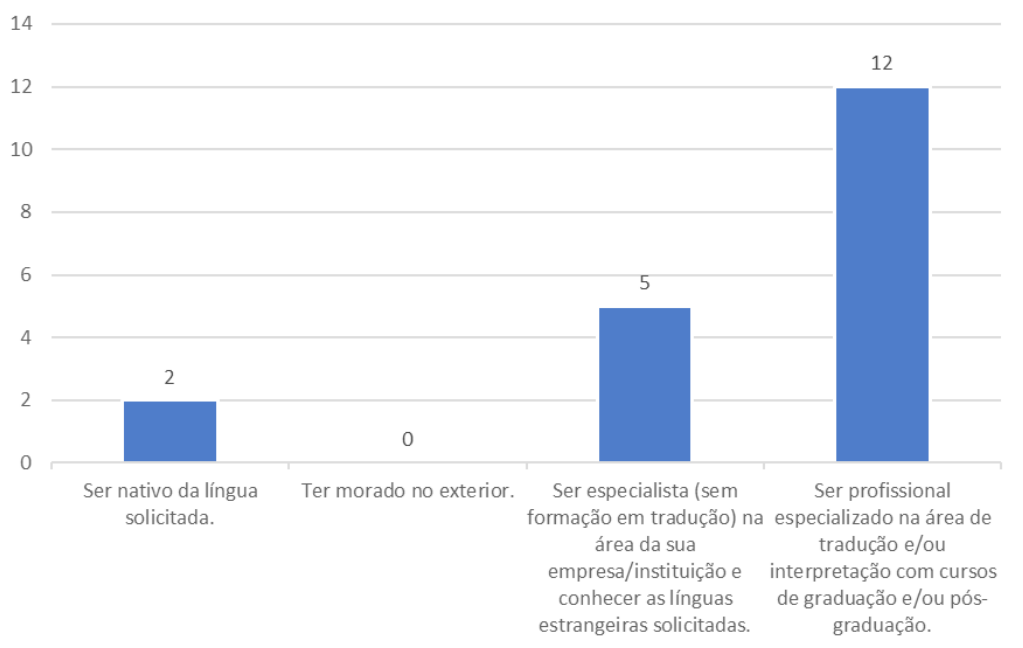

Fonte: Elaborado pelas autoras.

Na quinta pergunta, "Ao contratar um tradutor e/ou intérprete você se preocupa, ou se preocuparia, em saber que tipo de formação o profissional possui?", as opções eram "Sim", "Não" e "Outros", sendo que, nessa última, os respondentes poderiam escrever suas respostas. Obteve-se um total de 20 respostas para a pergunta e, entre elas, $85 \%$ foram "sim", $15 \%$ "outros" e nenhuma resposta "não". Na opção "Outros”, apareceram as seguintes respostas: "Se ele não for nativo de lá, sim"; "Não necessariamente, sem desmerecer quem 
estudou para isso"; "Sim, mas não seria o único fator determinante". Repete-se o ocorrido na questão anterior, ou seja, apesar de muitas pessoas se preocuparem com a formação do profissional contratado e demonstrarem perceber que existem diferenças entre as habilidades de um tradutor e/ou intérprete profissional e de um bilíngue sem formação ou experiência, essa percepção não é unânime.

Gráfico 5 - "Ao contratar um tradutor e/ou intérprete você se preocupa, ou se preocuparia, em saber que tipo de formação o profissional possui?"

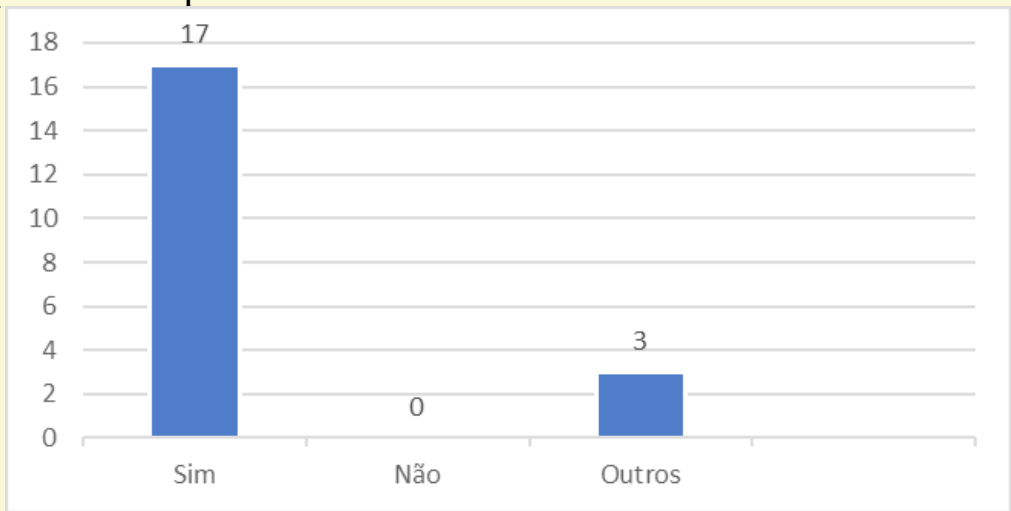

Fonte: Elaborado pelas autoras.

Em relação à sexta pergunta, "Para quais serviços você precisa, ou já precisou, do profissional de tradução e/ou interpretação na sua empresa/instituição?", foram inseridas as seguintes atividades: a) tradução e atualização do site da empresa e/ou instituição; b) tradução de contratos e de outros documentos comerciais; c) tradução de e-mails; d) tradução de catálogos e de outros produtos específicos da empresa e/ou instituição; e) interpretação em eventos; f) interpretação em reuniões e acompanhamentos; e g) outros. Os respondentes poderiam marcar mais de uma opção (informação incluída na pergunta do questionário) e utilizar também a opção "outros”. Para essa questão, 20 respondentes marcaram suas opções e, conforme podemos observar no gráfico 6 , os serviços mais utilizados 
são os dos itens “a” e "d", seguidos pelo item " $b$ " e, por último, os itens "e", "c" e "f". Na alternativa "outros" foram inseridas cinco respostas: "tradução de publicações científicas", "material de comunicação com empresas externas em duas línguas", "materiais publicitários destinados a turistas" e "atendimento aos turistas e gravação de áudios com informações turísticas”. Também ocorreu um caso em que o respondente escreveu "não precisamos".

De acordo com as respostas obtidas, podemos observar que o serviço de tradução e/ou interpretação é utilizado para atividades específicas da área de cada cliente. Esse resultado justifica os dados encontrados no gráfico 4 em que há a utilização de especialistas, sem formação/experiência em tradução e/ou interpretação, na área da empresa/instituição com conhecimento das línguas solicitadas.

Gráfico 6 - "Para quais serviços você precisa, ou já precisou, do profissional de tradução e/ou interpretação na sua empresa/instituição? Marque mais de uma opção, se necessário”.

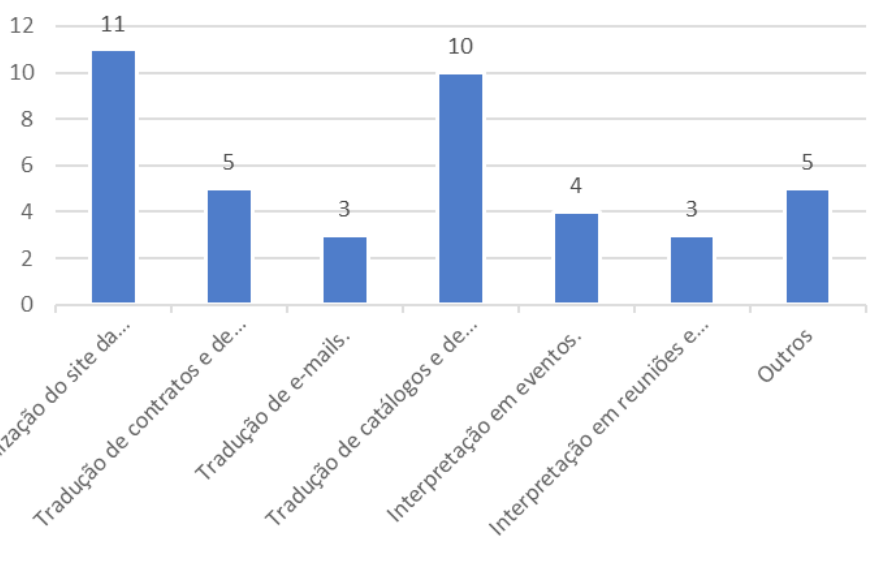

Fonte: Elaborado pelas autoras.

As duas últimas perguntas do questionário, "Você acredita que ser nativo em uma língua estrangeira é suficiente para desempenhar a atividade de tradução e/ou interpretação?" e "Você acredita que 
ter morado no exterior e aprendido a língua estrangeira é suficiente para desempenhar a atividade de tradução e/ou interpretação?", possuem por objetivo investigar a percepção de leigos quanto às habilidades dos bilíngues, tanto daqueles que são nativos quanto dos que tiveram a experiência de morar no exterior. Essas duas caracterizações se ajustam aos principais conceitos de bilinguismo abordados neste artigo. É oportuno relembrar aqui que, ao mencionarmos o termo "bilíngue", estamos nos referindo a alguém com conhecimento em duas línguas, mas sem formação e/ou experiência na área de tradução e/ou interpretação.

Assim, os gráficos 7 e 8 mostram que todos os participantes responderam as duas perguntas. Na sétima pergunta, quando perguntados se ser bilíngue, no caso, nativo, seria o necessário para desempenhar a atividade de tradução e/ou interpretação, 62\% dos participantes optaram por "nem sempre", 29\% disseram que ser nativo da língua estrangeira não é suficiente e apenas $9 \%$ acreditaram que ser nativo bastava.

Gráfico 7 - "Você acredita que ser nativo da língua estrangeira é suficiente para desempenhar a atividade de tradução e/ou interpretação?”

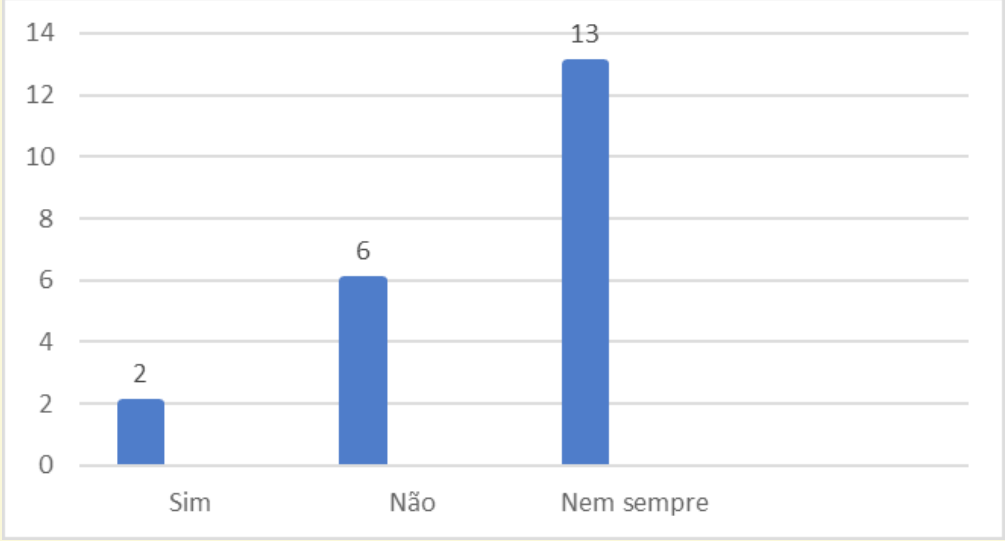

Fonte: Elaborado pelas autoras. 
A pergunta sete difere da pergunta oito pela condição do bilíngue. $\mathrm{Na}$ primeira, ele seria nativo, ao passo que, na segunda, morou no exterior e aprendeu outra língua. É possível perceber coerência na percepção dos participantes quanto às habilidades do bilíngue quando comparadas às do profissional especializado, uma vez que o gráfico 8 apresenta o mesmo resultado do gráfico anterior. Novamente, $62 \%$ dos participantes escolheram a alternativa "nem sempre", ou seja, morar no exterior e aprender a língua não é garantia de um bom desempenho da atividade de tradução e/ou interpretação, 29\% achava que apenas essa experiência não é suficiente e a minoria, 9\%, acreditava que sim, bastava ter morado no exterior.

Esses resultados mostram que a maioria dos respondentes tem consciência que ser bilíngue é uma condição necessária, mas não suficiente, para o desenvolvimento das atividades de tradução e/ou interpretação. Percebe-se que, apesar de alguns dos participantes preferirem contar com funcionários ou pessoas sem formação e/ou experiência em tradução/interpretação para executar traduções e/ ou interpretações, a maioria parece reconhecer o valor do profissional com formação e/ou experiência na área.

Gráfico 8 - "Você acredita que ter morado no exterior e aprendido a língua estrangeira é suficiente para desempenhar a atividade de tradução e/ou interpretação?"

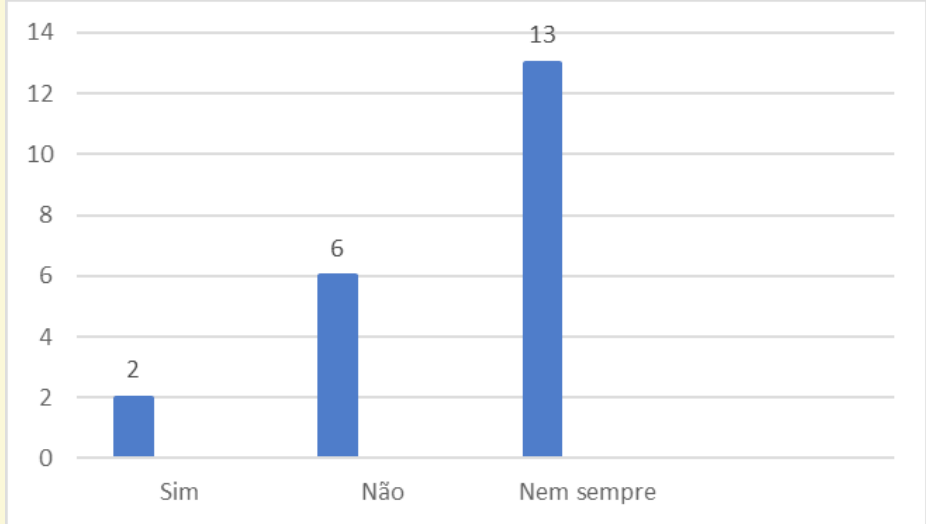

Fonte: Elaborado pelas autoras.

Cad. Trad., Florianópolis, v. 39, no 3, p. 90-110, set-dez, 2019. 
Quando as perguntas do questionário foram relacionadas à questão do ser profissional da área da tradução e/ou interpretação e o ser bilíngue sem formação e/ou experiência, os resultados apontaram que a maioria dos participantes se preocupa ou tem consciência de que a especialização é essencial para um bom tradutor e/ou intérprete. Esses resultados vão ao encontro dos resultados apresentados pelas pesquisas descritas na seção anterior, em que o treinamento, a técnica e a experiência nas atividades de tradução e/ou interpretação atestaram a vantagem dos profissionais sobre os bilíngues quando se trata de atividades relacionadas à área. Assim, foi possível constatar que, do ponto de vista dos clientes, existe um reconhecimento de que ser bilíngue é importante, mas não o bastante.

\section{Conclusão}

Tendo em vista os tópicos apresentados, podemos responder à pergunta inicial: Ser bilíngue é o suficiente para ser um bom tradutor ou intérprete? É necessário, mas não o único requisito para realizar uma boa tradução ou interpretação. Para a execução dessas atividades, o bilinguismo deve ser aliado à técnica, ao treinamento e à experiência.

Considerando o objetivo dessa pesquisa, de investigar o tipo de profissional preferido pelas pessoas que contratam serviços de tradução e/ou interpretação, tivemos um resultado inesperado. Os dados mostraram que a maioria dos participantes prefere contratar profissionais da tradução e/ou da interpretação a apenas bilíngues. Tal resultado não confirma nossa hipótese inicial, ou seja, que, na percepção dos clientes, a formação/experiência não seria importante e que o fato de o indivíduo ser bilíngue seria suficiente para traduzir ou interpretar. Talvez os participantes possam sofrer influência do fato de que se tratava de uma pesquisa universitária da área da tradução. Dessa forma, poderiam ter se sentido, conscientemente ou não, pressionados a valorizar a figura do profissional dessa área. 
Apesar dos limites em termos de número de participantes e prazos, este estudo traz para a área da tradução e interpretação uma visão importante acerca do seu cliente. Embora a maioria demonstre preferência pelo profissional da área da tradução/interpretação, ainda não existe conscientização unânime por parte dos clientes de que ser tradutor ou intérprete profissional requer habilidades diferentes das que o bilíngue possui e que, para traduzir e interpretar, é preciso ser bilíngue, mas também possuir técnica, treinamento e experiência.

Seria interessante conduzir outras pesquisas similares, com prazo e amostragem maior, a fim de se obter um resultado mais abrangente para complementar os dados aqui obtidos. Através de entrevistas presenciais, por exemplo, seria possível conseguir informações mais detalhadas sobre a percepção dos clientes e até mesmo sobre o tipo de serviço para o qual empresas e instituições utilizam a tradução e/ou interpretação.

\section{Referências}

Alexander, C., Edwards, R., Temple, B., Kanani, U., Zhuang, L., Miah, M., and Sam, A. Access to services with interpreters: User views. New York: Joseph Rowntree Foundation, 2004.

Bajo, M. T., Padilla, F., and Padilla, P. "Comprehension processes in simultaneous interpreting”. In: Chesterman, Andrew; Gallardo, Navidad and Gambier, Yves. Translation in Context: selected contribution from EST Congress. Granada, Spain. Benjamins translation library. Vol. 39. Amsterdam: John Benjamins, 2000.

Christoffels, I. Cognitive studies in simultaneous interpreting. Tese de doutorado. Universidade de Amsterdam, 2004. < http://hdl.handle.net/11245/ 1.253465>

Cad. Trad., Florianópolis, v. 39, no 3, p. 90-110, set-dez, 2019. 
Dillinger, M. "Comprehension during interpreting: What do interpreters know that bilinguals don't. Bridging the gap: Empirical research in simultaneous interpretation". The Interpreter's Newsletter 3 (1990): 155-189.

Hill, M. M., and Hill, A. Investigação por questionário. 2nd ed. Lisboa: Silabos, 2012.

Grosjean, F. "The bilingual's language modes". In: Grosjean, F. Explaining linguistics. One mind, two languages: Bilingual language processing. Malden: Blackwell, 2001.

Grosjean, F., and Li, P. The psycholinguistics of bilingualism. Chichester: John Wiley \& Sons, 2012.

Harris, B. "The Importance of Natural Translation". Working Papers on Bilingualism 12 (1977): 96-114.

Ibáñez, A. J., Macizo, P., and Bajo, M. T. "Language access and language selection in professional translators". Acta psychologica 135.2 (2010): 257-266.

Johnson, F. "Being Bilingual Is Not Enough". The ATA Chronicle 37.7 (2008): $22-25$.

Lörscher, W. "Bilingualism and Translation Competence". SYNAPS - A Journal of Professional Communication 27 (2012): 3-15.

Năznean, A. "Bilingualism versus translation". The Proceedings of the "European Integration-Between Tradition and Modernity" Congress, 5. Tirgu-Mures: Editura Universităţi Petru Maior, 2013.

Pompeu, A. C. M. A percepção dos clientes quanto aos serviços de tradução el ou interpretação: ser bilíngue é suficiente? Trabalho de conclusão de curso de Especialização. Pontifícia Universidade Católica do Rio Grande do Sul, 2018.

Schwieter, J. W., and Ferreira, A. "Bilingualism in Cognitive Translation and Interpreting Studies". In: Schwieter, J.W., and Ferreira, A. The Handbook of Translation and Cognition. Chichester: John Wiley \& Sons, 2017. 
Yudes, C., Macizo, P., and Bajo, T. "The influence of expertise in simultaneous interpreting on non-verbal executive processes". Frontiers in psychology 2 (2011): 1-9. <https://doi.org/10.3389/fpsyg.2011.00309>.

Recebido em: 18/02/2019 Aceito em: 20/07/19 Publicado em: Setembro de 2019

Ana Carolina Moura Pompeu. E-mail: anacmpompeu@gmail.com ORCID: https://orcid.org/0000-0002-9955-3515

Patrizia Cavallo. E-mail: patriziacavallo.ita@gmail.com ORCID: https://orcid.org/0000-0001-7955-8071 